\title{
Cara Allah Memberi Jalan Lewat Istikharah Aina Salsabila
}

\author{
Program Studi Pendidikan Guru Sekolah Dasar \\ Fakultas Keguruan dan Ilmu Pendidikan \\ Universitas Nahdlatul Ulama Sidoar jo \\ Email: salsabilaaina52@gmail.com
}

\section{Pengantar}

Bagi setiap orang yang dalam kehidupan mengharap kebahagiaan di dunia dan di akhirat untuk itu mewujudkannya tidak semudah seperti membuka telapak tangan. Di dunia ini adalah tempat segala hal sesuatu dan berkumpul, kebaikan, keburukan, kejahatan, keindahan, dan lainnya. Jika salah seorang mengenalinya ia akan ter jebak dan salah langkah. Disebabkan dari segala keterbatasan dan kelemahan indra manusia, kejahatan terkadang dapat terlihat menjadi suatu keburukan. Manusia adalah ciptaan tuhan maka semestinya menyerahkan segala hal urusan hidup kepada Allah SWT. (al-maduri, ट010)

Berdoa dan meminta petunjuk kepada Allah SWT adalah jalan terbaik agar terhindar dari kesesatan. Salah satunya yaitu dengan shalat istikharah. Shalat yaitu jalinan komunikasi dengan Allah SWT untuk bermunajat. Agama islam mengatur sesuatu dari ajaran yang sempurnah dan di rahmati. Oleh karna itu, masalah apapun akan ada penyelesaiannya. Shalat istikharah ialah jalan petunjuk dalam bimbingan ketika ada ketidak pastian menentukan pilihan serta menghadapi berbagai perkara dalam kehidupan.

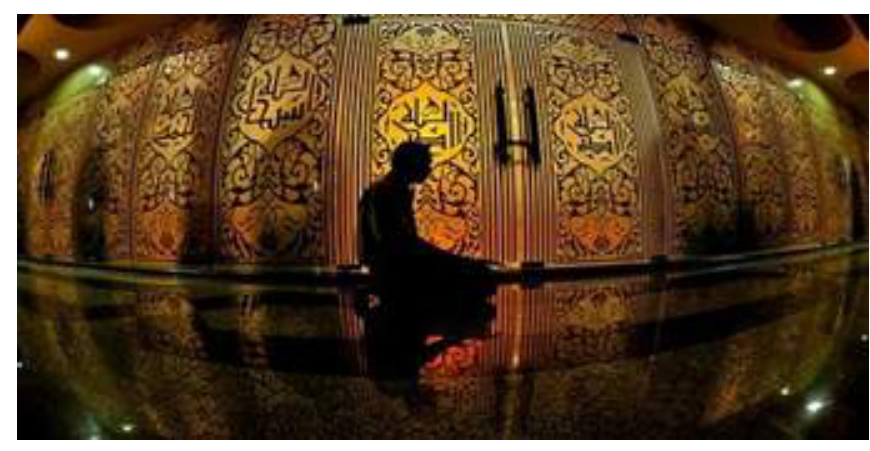




\section{Definisi Shalat Istikharah}

Istikharah adalah memohon kebaikan kepada Allah oleh seseorang yang akan melakukan satu perkara yang sedang dihadapi. Secara syara'lstikharah adalah doa khusus yang diucapkan seorang muslim telah mengajarkan shalat dua rakaat sunnah. Dalam doanya ia memohon kepada Rabbnya agar memilihkan yang terbaik baginya untuk melakukan sesuatu ( yang tidak melanggar syariat) atau tidak melakukannya sama sekali ( menggagalkan keinginan dan rencana). (al-maduri, 2010)

\section{Istikharah Untuk Pernikahan}

Shalat Istikharah yang dilakukan Rasulullah tidak hanya dilakukan untuk kepentingan berperang dan berjihad dijalan Allah atau untuk kepentingan Ilmu pengetahuan. Shalat Istikharah bisa dilakukan untuk kepentingan pernikahan. Seseorang dengan melakukan shalat Istikharah dapat meminta petunjuk dan hidayah langsung dari Allah. Dengan lewat shalat Istikharah seseorang memasrahkan sepenuhnya kepada kebijakan Allah yang maha bijaksana.

Seorang perempuan dan laki-laki yang hidup bersama juga disebut sunnatullah, alamiah, dan amat manusiawi. Pernikahan juga merupakan sesuatu yang dilakukan oleh semua Rasul dan utusan Allah. Membangun rumah tangga yang sakinah mawaddah warahma adalah keinginan setiap seorang perempuan dan laki-laki. Memiliki seorang istri yang setia, mencintai suaminya, merawat anak-anaknya dengan sepenuh hati dan selalu membangkitkan untuk bersemangat apabila kondisi suami dalam keadaan tidak baik secara psikologis, serta membantu suami dalam kesusahan adalah keinginan suami. Dan begitu juga, seorang suami yang setia, tidak akan selingkuh dengan perempuan lain, mampu bahagiakan istri, dan memberi kasih sayang dan tulus yang diinginkan oleh istri adalah keinginan seorag suami dalam pandangan perempuan.

Apabila kita menetukan pasangan hidup atau jodoh yang kurang baik sebelum pernikahan telah ter jebak pada kesalahan, maka hubungan rumah tangga yang dilangsungkan akan goyah ditengah perjalan. Di kehidupan rumah tangga mereka akan dipenuhi percekcokan dan ketidak harmonisan menjadi warna keseharian. Bahkan bisa berlanjut dan berlarut-larut sehingga menjadikan perceraian. Islam tidak menginginkan seseorang yang telah mengikat satu tali pernikahan dan telah melepaskannya, akan tetapi di dalam islam perceraian merupakan sesuatu yang boleh dilakukan. Hal yang dibenci Allah adalah perceraian. Yang artinya Islam mengharapkan 
semua Muslim untuk serius dalam urusan pernikahan dan membangun rumah tangga dengan keharmonisan, dan Islam menghendaki umatnya hancur lebur dalam menjalani rumah tangga.

Untuk itulah Islam mengajarkan tata cara tersebut supaya tidak terjerumus dalam perceraian. Islam mempunyai cara tertentu yang diker jakan oleh seseorang hendak melangsungkan akad pernikahan, Sebelumnya Allah akan memberi petunjuk bahwa pernikahan yang dilangsungkan itu baik atau buruk.

\section{A. Jodoh Yang Ideal}

Dalam menentukan pasangan hidup yang baik tergantung pada selera masing-masing orang. Setiap orang memiliki penilaian yang cocok dengan keinginannya hatinya. Semua muslim sejati, beriman kuat, dan bertakwah kokoh akan percaya bahwa pilihan yang berdasarkan pada hawa nafsu akan selalu berujung pada kesensaraan dan penyesalan. Sementara pilihan yang didasarkan pada kriteria-kriteria yang berdasarkan wahyu Tuhan adalah pilihan yang pasti membuahkan kebahagiaan dan ketenangan rumah tangga. (al-maduri, 2010)

Pada zaman Rasulullah berlangsung sebuah tradisi, yaitu orangorang ketika itu selalu berpijak pada empat macam kriteria untuk menentukan calon pasangan hidup. Selain dari empat kriteria tersebut belum pernah terjadi di zaman Rasulullah Saw. Sendiri.

Dalam pandangan agama Islam, perempuan yang beragama baik akan lebih membawa keberuntungan dalam sebuah rumah tangga daripada beristrikan perempuan yang tidak memiliki sifat dan sikap religiusitas tinggi. Dan begitu pula, suami yang shaleh dan beragama baik akan lebih membawa kebahagiaan dalam kehidupan rumah tangga daripada bersuamikan seseorang yang tingkat keteguhannya berpegangan pada agama sangat minim. Artinya sifat religius seseorang adalah patokn yang bisa dijadikan barometer untuk menilai calon yang manakah yang sesuai dengan pilihan hati.

\section{B. Meminta Pendapat Orang Lain}

Sebelum melangsungkan pernikahan, lebih baik mencari pendapat dan informasi dari pihak lain tentang kepribadian calon pasangan. Setelah mantab hati dan berkeyakinan yang dipilih adalah baik, maka laksanakan shalat dua rakaat istikharah untuk mendapatkan pertimbangan dari Allah. Ada dua tahap yang perlu diminta kepada seorang yang akan menikah dengan lawan jenisnya, yang pertama meminta pertimbangan kepada sesama manusia,kedua memasrahkan segala urusannya kepada Allah lewat shalat Istikharah. (al-maduri, टOIO) 
Ketika seseorang Muslim mengalami kesusahan dalam hidupnya, dia akan bermusyawarah dengan oarng yang di sekitarnya dan memasrahkan kepada Allah lewat shalat Istikharah. Sebab itu, tidak ada kemungkinan untuk gagal sangat sempit.

\section{Menjaga Kebersihan Hati}

Dalam menentukan jodoh, siapa calon suami dan calon istri yang layak dijadikan pasangan tergantung kepada kecenderungan hatinya. Nah, apabila hatinya kotor adalah mungkin bahwa pilihannya akan memilih salah, tertutup dari kebenaran, dan akhirnya calon pasangan yang dia pilih tidak akan memberi apapun kecuali yang buruk pula. (al-maduri, zOlO)

Suasana hati adalah sangat penting. Apabila tercipta suasana hati yang sangat agamis dan regilius, maka dapat dipastikan pilihannya jatuh pada orang yang sama agamis dan sama religiusnya.

\section{Kebahagiaan Yang Selama ini Manusia Cari}

Istikharah merupakan jalan yang ditawarkan oleh agama Islam, agama yang diturunkan langsung oleh Allah dari atas langit, kepada seorang Nabi paling mulia sepanjang sejarah manusia. Tujuan utama shalat Istikharah tidak lain dan tidak bukan, hanya untuk memberi jalan kemudahan bagi manusia dalam mencapai kebahagiaan hidup supaya setiap usaha dan tindakannya benardan berada di atas jalan yang lurus.

\section{A. Tentang Kebahagiaan}

Orang yang berbahagia adalah orang yang mengambil pelajaran dari orang lain dan orang yang celaka adalah orang yang dijadikan pelajaran oleh orang lain (pelajaran buruk). (al-maduri, टO10)

Orang bahagia adalah orang yang mengambil pelajaran dari masalalu dan berhati-hati terhadap dirinya. Orang yang mampu menerima takdir Allah dengan lapang dada.

\section{B. Petunjuk Menuju Kebahagiaan}

Untuk menuju kebahagiaan, banyak sekali jalan yang bisa di 
tempuh oleh semua orang, utamanya umat Muslim. Mulai dari yang ringan semisal membantu orang lain, bersilaturrahim, bersedekah, dan lain sebagainya, hingga sampai dengan menggunakan jalan yang berat. Terkadang kebahagiaan dapat terlihat dari pancaindra. (almaduri, टOlO)

Kebahagiaan memiliki tanda-tanda yang mampu di tangkap oleh pancaindra manusia.

\section{Penutup}

Bagi setiap orang yang dalam kehidupan mengharap kebahagiaan di dunia dan di akhirat untuk itu mewujudkannya tidak semudah seperti membuka telapak tangan. Di dunia ini adalah tempat segala hal sesuatu dan berkumpul, kebaikan, keburukan, kejahatan, keindahan, dan lainnya. Jika salah seorang mengenalinya ia akan ter jebak dan salah langkah. Disebabkan dari segala keterbatasan dan kelemahan indra manusia, kejahatan terkadang dapat terlihat menjadi suatu keburukan. Manusia adalah ciptaan tuhan maka semestinya menyerahkan segala hal urusan hidup kepada Allah SWT.

Dalam menentukan pasangan hidup yang baik tergantung pada selera masing-masing orang. Setiap orang memiliki penilaian yang cocok dengan keinginannya hatinya. Semua muslim sejati, beriman kuat, dan bertakwah kokoh akan percaya bahwa pilihan yang berdasarkan pada hawa nafsu akan selalu berujung pada kesensaraan dan penyesalan. Sementara pilihan yang didasarkan pada kriteria-kriteria yang berdasarkan wahyu Tuhan adalah pilihan yang pasti membuahkan kebahagiaan dan ketenangan rumah tangga.

\section{References}

Purnomo, A. (2008). Bekerja Produktif Berbasis Cinta kepada Allah. In The Spirit of Love Rahasia Bagaimana Cinta Membuat Hidup Lebih Produktif. Yogyakarta: Bukulaela.

Anas, Fathul, akk. 2010. Kuraih Bahagia Dengan Istikharah; Seteres Embun Hidayah Bagi Hati yang Gundah. Yogyakarta: Lallery Ilmu.

Ayyash, Muhammad Abu. 2008. Keajaiban Shalat Istikharah; Menentukan Pilihan Sesuai Petunjuk Tuhan. Jakarta Selatan: QultumMedia.

Hamdan. Ahmad Zayid. 2008. Shalat Istikharah; Rahasia Menentukan Keputusan Dengan Cepat dan Tepat. Solo: AQWAM.

Khalil. M.S. 2006. Tata Cara Shlata Nabi Muhammad Saw. Yogyakarta: 1zzan pustaka. Riyadh, Saad. ¿007. Jiwa Dalam Bimbingan Rasulullah Saw. (ter i.). Jakarta: Cema Insani.

Syafi'i, Abdullah. 2000. Tuntunan Shalat Istikharah dengan Hari Raya. Surabaya: ARLOKA. 